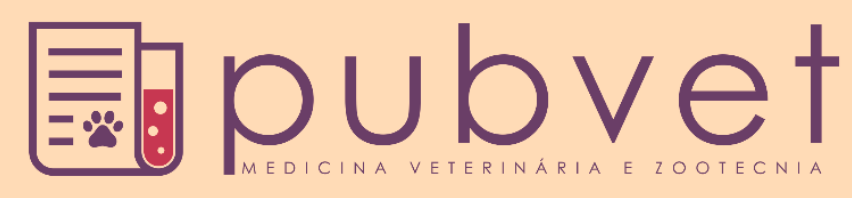

https://doi.org/10.31533/pubvet.v13n5a330.1-8

\title{
Análise de psicrotróficos e psicrotróficos proteolíticos em iogurte integral
}

\author{
Márcia de Lima Ferreira ${ }^{1}$, Giovanna Lima Palhares $^{2}$, Anderson de Araújo Silva ${ }^{1}$, Stefania \\ Marcia de Oliveira Souza ${ }^{3}$ o
}

${ }^{1}$ Graduanda em Medicina Veterinária no Centro Universitário ICESP, Águas Claras-DF, Brasil.

${ }^{2}$ Médica Veterinária Brasília-DF-Brasil.

${ }^{3}$ Professora de Medicina Veterinária das Centro Universitário ICESP, Águas Claras-DF, Brasil.

*Autor para correspondência,E-mail: marciadelimaferreira@gmail.com.

Resumo. O iogurte integral é um alimento muito consumido no Brasil, porém, como qualquer derivado lácteo, é susceptível a contaminações. Objetivou-se neste trabalho detectar a presença de bactérias psicrotróficas e psicrotróficas proteolíticas em iogurte integral, uma vez que essas são bactérias indicadoras de sua qualidade microbiológica. Os resultados encontrados não foram satisfatórios para a contagem de psicrotróficos, pois apesar da legislação brasileira não estipular limites máximos para esses microrganismos, sua presença é indesejada por causarem prejuízos econômicos, entre outros problemas. Foram realizadas quatro análises durante o período de validade do iogurte, a primeira amostra (dia 0) apresentou uma contagem de $8,0 \times 10^{2}$, a segunda (dia 7$)$ teve a sua redução em $50 \%,\left(4,0 \times 10^{2}\right)$ a terceira amostra (dia 21$)$, $0,5 \times 10^{2}$ e a última análise (dia 28) houve resultado negativo. Para a contagem de psicrotróficos proteolíticos, não houve detecção de microrganismos viáveis. Conclui-se que (apesar de esforços para manter a qualidade) há falhas no processo de fabricação, frisando a necessidade de controle nas etapas de produção do iogurte e na obtenção de um leite com boa qualidade, já que este é a principal matéria prima na produção do iogurte.

Palavras chave: Qualidade microbiológica, derivado lácteo, segurança alimentar

\section{Analysis of psychrotrophics and proteolytic psychrotrophics in integral yoghurt}

Abstract. Whole yogurt is a very consumed food in Brazil, but like any dairy derivative, susceptible to contamination. The objetive of the work was to detect the presence of psychrotrophic and proteolytic psychrotrophic bacterium in whole yoghurt, since these are bacterium indicative of their microbiological quality. The results found were not satisfactory for the psychrotrophic count, because although Brazilian legislation does not stipulate maximum limits for these microorganisms, their presence is undesirable because they cause economic losses, among other problems. Four analyzes were carried out during the period of validity of the yogurt, where the first sample (day 0 ) had a count of $8.0 \times 10^{2}$, the second one (day 7) had a reduction of $50 \%,\left(4.0 \times 10^{2}\right)$ The third sample (day 21), $0.5 \times 10^{2}$ and the last analysis was negative. In order to count proteolytic psychrotrophics, there was no detection of viable microorganisms, but despite this, their enzymes can act on the yogurt components causing changes, which was not evaluated in the present research. It is concluded that despite efforts to maintain quality, there are still shortcomings in the manufacturing process, stressing the need to control the production stages of yogurt and obtaining a milk with good quality, since this is the main raw material in the production of yogurt. 
Key words: Microbiological quality, milk derivatives, food safety

\title{
Análisis de psicrótrofos y psicrótrofos proteolíticos en el yogur integral
}

\begin{abstract}
Resumen. El yogur integral es un alimento muy consumido en Brasil, pero como cualquier derivado lácteo, es susceptible a la contaminación. Se objetivó en este trabajo detectar la presencia de bacterias psicrótroficas y proteolíticas psicrótroficas en el yogur integral, ya que son bacterias indicativas de su calidad microbiológica. Los resultados encontrados no fueron satisfactorios para el recuento de psicrótrofos, pues, aunque la legislación brasileña no establecer límites máximos para dichos microorganismos, su presencia es indeseable porque causa pérdidas económicas, entre otros problemas. Se realizaron cuatro análisis durante el período de validez del yogur, donde la primera muestra (día 0 ) tuvo un conteo de $8.0 \times 10^{2}$, la segunda (día 7) tuvo una reducción del 50\%, $\left(4.0 \times 10^{2}\right)$. Tercera muestra (día 21$), 0.5 \times 10^{2}$ y el último análisis (día 28) fue negativo. Para contar los psicrotróficos proteolíticos, no se detectaron microorganismos viables. Se concluye que, a pesar de los esfuerzos por mantener la calidad, todavía existen deficiencias en el proceso de fabricación, lo que destaca la necesidad de controlar las etapas de producción del yogur y obtener una leche de buena calidad, ya que es la principal materia prima en la producción de yogur.
\end{abstract}

Palabras clave: Calidad microbiológica, derivado lácteo, seguridad alimentaria

\section{Introdução}

O leite e seus derivados constituem alimentos que estão em crescente aumento de produção e consumo no Brasil, um exemplo é o iogurte integral, que serve como base para outros tipos de iogurte e apresenta grande qualidade e importância nutricional. No seu processo de fabricação, são adicionadas bactérias selecionadas como Lactobacillus bulgaricus e Streptococcus termophilus (BRASIL, 2011; Grandi \& Rossi, 2010).

O controle, monitoramento da qualidade, produção e o modo como esses iogurtes são armazenados e expostos, são essenciais para garantir a qualidade do produto durante toda a vida de prateleira. Esse controle e monitoramento devem ser feitos por meio de análise organoléptica, sensorial e microbiológica, onde esta última tem como objetivo identificar os microrganismos que apresentam crescimento ótimo em baixas temperaturas, (já que o iogurte deve ser armazenado dessa forma) que podem alterar a qualidade e diminuir o tempo de prateleira do alimento, caso estes microrganismos estejam presentes em grandes quantidades (Oliveira et al., 2018). Para garantir que os benefícios do produto estejam presentes, é necessário obter um leite de qualidade e com contagem de bactérias inicialmente baixa, já que o emprego do resfriamento para a conservação do leite e derivados, sem a realização de medidas higiênicas adequadas durante o processo de obtenção da matéria-prima, propicia a multiplicação de microrganismos proteolíticos e psicrotróficos (Matsubara et al., 2011).

O objetivo do presente trabalho foi verificar e quantificar a presença de microrganismos psicrotróficos e psicrotróficos proteolíticos em iogurte integral.

\section{Material e métodos}

Foram adquiridas 4 unidades de iogurte integral provenientes do mesmo lote, marca e estabelecimento comercial, as quais foram acondicionados em caixas isotérmicas contendo gelo, e enviadas ao laboratório de microbiologia para a realização das análises. Todos os produtos foram adquiridos na região de Brasília - DF, sendo estes registrados pelo sistema de inspeção.

O estudo foi realizado no Laboratório de Microbiologia do Centro Universitário ICESP, Águas Claras DF, no período de fevereiro e março de 2019. Cada amostra foi analisada nos períodos de $0,7,21$ e 28 dias de estocagem, em temperaturas de $7 / 8^{\circ} \mathrm{C}$, sendo cada unidade aberta no momento da análise, dentro do mês de validade determinado no rótulo. 
Para análise de psicrotróficos foi realizado protocolo conforme descrito por Santos et al. (2009). Foram preparadas diluições decimais seriadas das amostras pipetando-se assepticamente $25 \mathrm{~mL}$ da amostra e transferindo-as para um Erlenmeyer contendo $225 \mathrm{~mL}$ de água peptonada 0,1\% (diluição $10^{-1}$ ). A partir dessa diluição, foi preparada diluição até $10^{-2}$, empregando se o mesmo diluente. Uma vez diluídas, foram adicionados $1 \mathrm{~mL}$ da diluição $10^{-2} \mathrm{em}$ placas de Petri esterilizadas contendo ágar padrão para contagem, fundido, resfriado a $45^{\circ} \mathrm{C}$ e homogeneizado (APHA, 2014). Esse procedimento foi realizado em duplicata. Após a solidificação do ágar em temperatura ambiente, foram incubadas placas invertidas a $7^{\circ} \mathrm{C} / 10$ dias (Marshall et al., 2003). Para o cálculo do número de UFC/mL da amostra, foi feita a média do número de colônias das placas e multiplicou se o valor pelo fator de diluição inoculada.

Para contagem de microrganismos psicrotróficos proteolíticos, foi utilizado o mesmo procedimento de diluição realizado na análise de psicrotróficos. Após a realização das diluições decimais, foi adicionado 1 $\mathrm{mL}$ das diluições em placas de Petri esterilizadas, contendo Agar leite (ágar padrão acrescido de $10 \%$ de leite em pó desnatado, fundido e resfriado a $45^{\circ} \mathrm{C}$ ). As placas foram incubadas a $21^{\circ} \mathrm{C} / 72$ horas como preconizado por Marshall et al. (2003). As colônias de microrganismos proteolíticos apresentam-se rodeadas por uma zona clara, o que é resultado da conversão da caseína em compostos nitrogenados solúveis. A contagem foi efetuada através da observação de colônias que possuírem um halo transparente ao seu redor e foi calculado o número de $\mathrm{UFC} / \mathrm{mL}$ da amostra multiplicando o número de colônias, em cada placa, pelo fator de diluição.

\section{Resultados e discussão}

Os produtos lácteos assumem papel positivo no mercado alimentício, devido ao crescente aumento no seu consumo pela população nacional e internacional, fazendo com que cresça a preocupação em desenvolver estudos para a melhoria de sua qualidade (Soares et al., 2011). Segundo a Instrução Normativa 46/2007 do Ministério da Agricultura, Pecuária e Abastecimento (MAPA), os iogurtes são considerados leites fermentados e são por definição, produtos adicionados ou não de outras substâncias alimentícias, obtidos por fermentação láctica mediante ação de cultivos de microrganismos específicos como Lactobacillus bulgaricus e Streptococcus termophilus. Esses microrganismos específicos devem ser viáveis, ativos e abundantes no produto final durante seu prazo de validade (BRASIL, 2011).

Os leites fermentados, em geral, são importantes para a nutrição humana, porque apresentam melhor digestibilidade do que o leite. Isso se dá pelo fato de seus constituintes já serem pré-digeridos devido ao processo fermentativo ao qual são submetidos no processamento. Além disso, apresenta conteúdo reduzido de lactose, importante para a população intolerante; aumenta a absorção de ferro; aumenta 0 conteúdo de algumas vitaminas tipo B; controla a composição da microbiota intestinal; inibe a multiplicação de microrganismos patogênicos no trato intestinal e ainda diminui o nível de colesterol no sangue quando consumido regularmente (Ril et al., 2011; Reis et al., 2014).

Em relação à composição geral, o iogurte integral tem um valor nutricional correspondente à composição do leite integral do qual são fabricados, apesar de uma maior formação de ácido láctico e por consequência diminuição da lactose (Grandi \& Rossi, 2010). Devido a sua quantidade de gordura, no qual a legislação brasileira estipula um mínimo de 3,0 g/100 g, sua predisposição ao crescimento bacteriano é consequentemente maior em comparação a outros tipos de leite fermentado visto que este componente serve como nutriente utilizado pelo metabolismo bacteriano (BRASIL, 2011).

A qualidade do iogurte depende do grau de contaminação do leite, ou seja, sua qualidade microbiológica e da temperatura no qual o mesmo permanece até o seu processamento na indústria (Cunha Neto et al., 2005). De acordo com a Instrução Normativa 62/2011 do MAPA, o leite cru deve ser refrigerado a $4{ }^{\circ} \mathrm{C}$ após a ordenha e armazenado na propriedade rural por no máximo 48 horas. Essa obrigatoriedade busca a diminuição da multiplicação de alguns microrganismos, mas propicia a multiplicação de bactérias psicrotróficas (Arcuri et al., 2008; BRASIL, 2011). 
Segundo Silva et al. (2011), a principal etapa da contaminação do leite é a ordenha, porém, a baixa qualidade do produto é devido a deficiências no manejo em várias etapas da produção como: sanidade da glândula mamária, desinfecção inadequada dos equipamentos e refrigeração deficiente. Assim, para a obtenção de um derivado lácteo de qualidade e sem altas contagens de microrganismos deteriorantes, os cuidados higiênicos devem ter início desde a ordenha até o seu beneficiamento pelas boas práticas de produção e fabricação (Matsubara et al., 2011).

Mesmo com o consumidor, cada vez mais consciente e informado quanto aos produtos oferecidos nos mercados, estudos ainda apresentam condições microbiológicas insatisfatórias para os derivados do leite (Andrade et al., 2014; Cunha Neto et al., 2005; Leite Júnior, 2013; Reis et al.,2014). Os derivados do leite são alimentos altamente susceptíveis à contaminação por fornecerem um ótimo meio de cultivo bacteriano e por terem uma carga proteica e lipídica alta. Sua degradação por meio de bactérias e suas toxinas se tornam incontroladas, se não forem bem manipuladas e armazenadas (Paixão et al., 2017; Rodrigues et al., 2012).

Segundo Santana et al. (2001), os psicrotróficos e psicrotróficos proteolíticos são microrganismos muito importantes dentro do mercado lácteo mundial, pois são capazes de se multiplicar em temperaturas de refrigeração, independentemente de sua temperatura ótima de crescimento. Mesmo em temperaturas de 7 ${ }^{\circ} \mathrm{C}$, os microrganismos psicrotróficos encontram-se em condições favoráveis para o seu desenvolvimento e podem tornar-se dominantes na microbiota do leite (Santana et al., 2001; Santos et al., 2009). Ainda hoje não existem parâmetros nas legislações vigentes sobre os valores permitidos para psicrotróficos, porém, estes microrganismos causam importantes processos deteriorantes no leite e nos seus derivados. Além disso, eles podem ser considerados grandes indicadores da qualidade dos alimentos, pois sua presença se dá por deficiências nos processos de limpeza e sanitização dos equipamentos utilizados em sua fabricação (Reis et al., (2014). Os microrganismos psicrotróficos são deteriorantes porque produzem enzimas proteolíticas e lipolíticas que são excretadas durante a estocagem do produto e antes do seu processamento. Apesar da maioria das bactérias psicrotróficas não sobreviverem à pasteurização, suas enzimas são termo resistentes, podendo resistir até mesmo ao tratamento UHT. Estas enzimas causam alterações nas características químicas e consequentemente sensoriais nos produtos lácteos; além de reduzir sua qualidade nutricional, por reduzir a quantidade total de proteínas e gorduras (Arcuri et al., 2008; Zeni et al., 2013). As principais bactérias psicrotróficas e psicrotróficas proteolíticas encontradas em subprodutos são Gram negativas dos gêneros Pseudomonas, Achromobacter, Aeromonas e Alcaligene (Ângelo et al., 2014). Todavia, de acordo com Bastos et al. (2012), os microrganismos psicrotróficos abrangem ainda aproximadamente 15 gêneros diferentes, incluindo bactérias Gram-positivas, bacilos, cocos, víbrios, formadores ou não de esporos, microrganismos aeróbios, anaeróbios e ainda alguns gêneros de bolores e leveduras.

Os resultados para análise de detecção e quantificação de psicrotróficos e psicrotróficos proteolíticos em amostras de iogurte integral estão demonstrados na tabela 1. As contagens de bactérias psicrotróficas e psicrotróficas proteolíticas foram realizadas ao final dos períodos de armazenagem pré-estabelecidos, em meios de cultivo previamente estéreis, assim como todo o material utilizado nas análises, evitando assim contaminações adversas, de acordo com Santos et al. (2009). A figura 1 demonstra o crescimento de psicrotróficos em Iogurte integral no dia 0 de armazenamento a temperatura de geladeira.

Tabela 1. Resultados da detecção de psicrotróficos e psicrotróficos proteolíticos em iogurte integral

\begin{tabular}{lcc}
\hline Dias de armazenamento do iogurte integral a $7^{\circ} \mathrm{C}$ & Psicrotróficos (UFC/g) & Psicrotróficos Proteolíticos (UFC/g) \\
\hline Dia 0 & $8,0 \times 10^{2}$ & 0 \\
Dia 7 & $4,0 \times 10^{2}$ & 0 \\
Dia 21 & $0,5 \times 10^{2}$ & 0 \\
Dia 28 & 0 & 0 \\
\hline
\end{tabular}

No dia 0 , houve um crescimento de $8,0 \times 10^{2} \mathrm{UFC} / \mathrm{g}$ para a contagem de bactérias psicrotróficas. No dia 7, o número de bactérias psicrotróficas reduziu em $50 \%$, sendo encontradas 4,0x10 ${ }^{2} \mathrm{UFC} / \mathrm{g}$. No 21 dia de armazenamento do iogurte, a contagem total reduziu para $0,5 \times 10^{2} \mathrm{UFC} / \mathrm{g}$ e no último dia de análise (D28), 
os resultados foram negativos para bactérias psicrotróficas. Estes resultados demonstram que o tempo de armazenagem do iogurte integral causou uma redução no número de microrganismos psicrotróficos o que sugere que os nutrientes presentes na amostra de iogurte podem estar sendo consumidos gradativamente pelos microrganismos causando sua diminuição e consequente redução no desenvolvimento dos microrganismos. Os resultados obtidos foram semelhantes aos descritos por Souza et al. (2012), que ao analisar queijo minas frescal a $4{ }^{\circ} \mathrm{C}$, por 10 dias, observou um aumento inicial na contagem de microrganismos psicrotróficos e com o passar do tempo essa contagem foi declinando por consequência do aumento da população microbiana, já que cresce também a competição desses microrganismos entre si pelo alimento.

Os valores obtidos são considerados altos se comparados com relatados por Reis et al. (2014) que analisou 65 amostras de iogurte de laticínios do Distrito Federal, que apresentaram valor máximo de 1,9 x $10^{1}$ UFC/g. Já em relação a Lima (2015), no qual o iogurte analisado apresentou contagens de bactérias psicrotróficas na ordem de $10^{3}$ a $10^{5} \mathrm{UFC} / \mathrm{g}$, as amostras analisadas na presente pesquisa demonstraram uma melhor qualidade microbiológica em relação a contagem de psicrotróficos, sugerindo uma forma de obtenção do produto realizada de maneira mais higiênica.

Santos et al. (2009) obtiveram 83,3\% das amostras de leite cru com contagens acima de $10^{7} \mathrm{UFC} / \mathrm{mL}$ de bactérias psicrotróficas totais. Quando as contagens de bactérias psicrotróficas no iogurte são comparadas a sua contagem no leite cru, já é esperado que os valores encontrados sejam menores por causa dos processos de termização aplicados, que buscam através de um binômio de tempo e temperatura, eliminar microrganismos patogênicos, porém níveis elevados de contaminação no leite acarretam a redução do rendimento na fabricação de derivados quando a contagem da população de psicrotróficos excede $10^{6} \mathrm{UFC} / \mathrm{mL}$ de leite. Segundo Bastos et al. (2012) existe uma predominância de bactérias psicrotróficas gram-negativas como as do gênero Pseudomonas $(81,2 \%)$ em leites pasteurizados, no qual a maioria apresenta atividade proteolítica a temperaturas de refrigeração, o que pode levar a deterioração do produto.

Nos dias 0 e 7, além do crescimento de microrganismo psicrotróficos, foi também observado presença de leveduras nas placas em função da morfologia das colônias como mostra a figura 2. Estes microrganismos podem estar presentes em alguns tipos de leites fermentados. Os bolores e leveduras causam deterioração de derivados lácteos por também apresentar características do grupo dos psicrotróficos (Santos et al., 2009; Zeni et al., 2013).

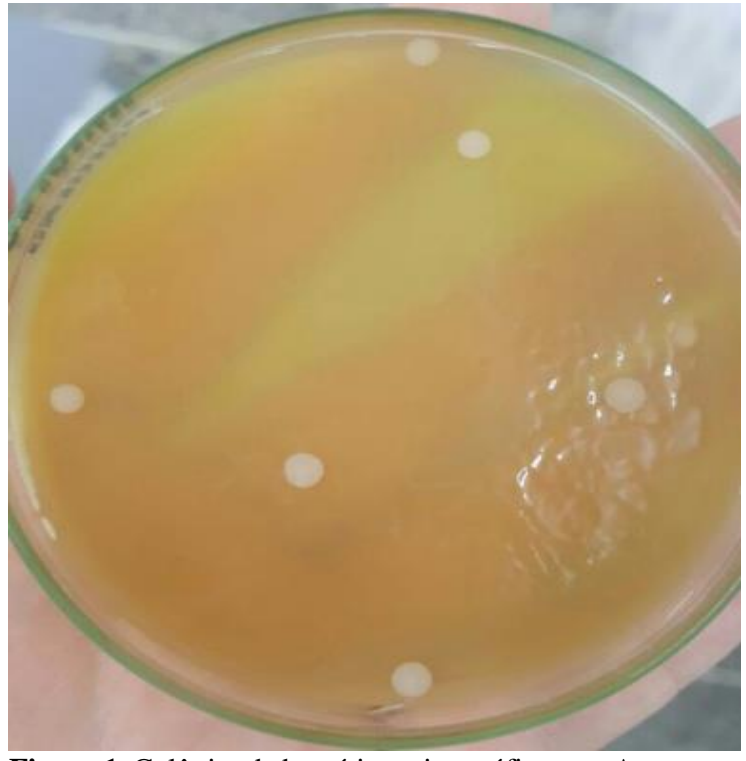

Figura 1. Colônias de bactérias psicrotróficas em Agar

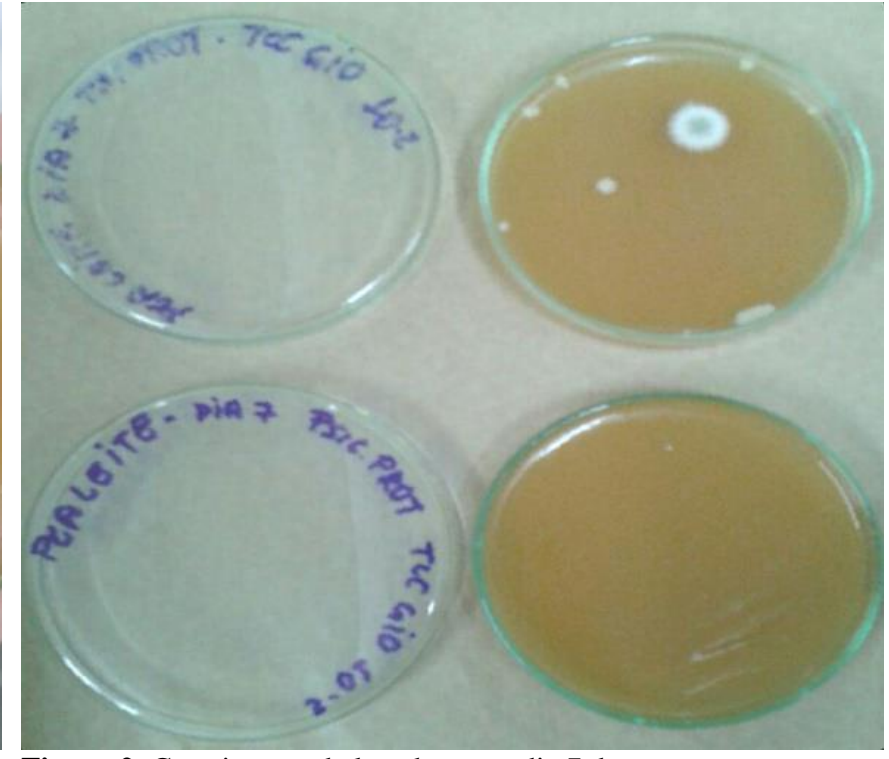

Figura 2. Crescimento de leveduras no dia 7 de armazenagem. 
leite realizada no dia 0 de armazenagem.

Segundo Coelho et al. (2009), este fato indica uma diminuição do pH do iogurte pelo acúmulo de ácido láctico, que por sua vez inibe o crescimento de bactérias lácticas, o que propicia o crescimento de bolores e leveduras. Esta contagem precisa ser mais bem investigada, pois algumas leveduras podem produzir etanol durante a fermentação, o que não é permitido para os leites fermentados em geral (BRASIL, 2011).

A legislação brasileira estabelece um limite mínimo de $107 \mathrm{UFC/g}$ para as bactérias láticas totais no iogurte durante toda sua vida de prateleira para que pelo menos, aproximadamente, $103 \mathrm{UFC} / \mathrm{g}$ alcancem os intestinos (BRASIL, 2011). A presença das bactérias lácticas influência na manutenção da inocuidade dos iogurtes, pois estes agem por antagonismo direto contra várias espécies patogênicas pela produção de bacteriocinas e por produção de enzimas que melhoram a digestão ou detoxificam os metabólitos da microbiota patogênica (Soares et al., 2011). Além disso, o ácido lático produzido por essas bactérias é o principal responsável pelo aumento da vida útil dos iogurtes em aproximadamente 30 dias, pois ele também passa a inibir bactérias gram negativas, principal gênero de microrganismos psicrotróficos encontrados nos derivados lácteos (Coelho et al., 2009; Finco et al., 2011).

Em relação à psicrotróficos proteolíticos, nenhum microrganismo foi encontrado durante o período de análise do iogurte. A detecção de bactérias psicrotróficas proteolíticas baseia-se na visualização da formação de halos de proteólise nas placas de Agar (Nörnberg et al., 2009). Pereira et al. (2008) explicam que o não aparecimento de bactérias psicrotróficas proteolíticas, não indica um derivado íntegro, já que o tratamento térmico do leite inativa essas bactérias, porém suas enzimas continuam ativas no produto. Isto sugere que apesar de não ter sido possível a detecção de microrganismos viáveis nas amostras, suas enzimas podem agir sobre os componentes do derivado lácteo causando alterações de sabor e odor, o que não foi avaliado na presente pesquisa.

Esse resultado se assemelha ao de Santana et al. (2001), que ao analisarem diferentes marcas de leites fermentados, algumas delas não apresentaram presença de psicrotróficos proteolíticos. $\mathrm{O}$ autor explica que esse resultado pode ter ocorrido por haver inicialmente, um aumento no crescimento das bactérias lácticas presentes no iogurte que produzem compostos de ação antimicrobiana, inibindo o crescimento de outros microrganismos, incluindo os determinados nas contagens realizadas no presente estudo.

\section{Conclusão}

Concluí se que a análise do iogurte integral no presente trabalho, resultou em quantidades significativas de bactérias psicrotróficas, o que sugere que há necessidade de maior controle nas etapas de produção e armazenamento e sanitização dos estabelecimentos produtores de iogurte, além do controle do leite usado em sua fabricação, pois estas bactérias podem levar a prejuízos para a indústria processadora e para consumidores. Não foram encontradas evidências de microrganismos psicrotróficos proteolíticos no iogurte, o que não o isenta de ter a presença de enzimas proteolíticas, já que elas são termo resistentes. Demostrando assim a necessidade de mais testes específicos, a fim de verificar a qualidade microbiológica do produto final.

\section{Referências bibliográficas}

Andrade, K. D., Rangel, A. H. N., Araújo, V. M., Medeiros, H. R., Bezerra, K. C., Bezerril, R. F. \& Lima Júnior, D. M. (2014). Qualidade do leite bovino nas diferentes estações do ano no estado do Rio Grande do Norte. Revista Brasileira de Ciência Veterinária, 21(3):213-216.

Ângelo, F. F., Ribeiro, C. S., Oliveira, L., Araujo, T. F. \& Cardarelli, H. R. (2014). Bactérias psicrotróficas em leite cru refrigerado. Revista Científica de Medicina Veterinária, 22(1):1-14.

APHA. (2014). Standard methods for the examination of water and wastewater (Vol. 20): American Public Health Association. 
Arcuri, E. F., Silva, P. D. L., Brito, M. A. V. P., Brito, J. R. F., Lange, C. C. \& Magalhães, M. M. A. (2008). Contagem, isolamento e caracterização de bactérias psicrotróficas contaminantes de leite cru refrigerado. Ciência Rural, 38(8).

Bastos, P. B., Gonsales, J. M., Almeida, L. M. N., Martins, R. S. \& Florentino, E. R. (2012). Contagem de bactérias psicrotróficas e diferenciação comparativa pós-termização em leites pasteurizados. Paper presented at the ENECT, Anais do Encontro Nacional de Educação, Ciência e Tecnologia UEPB, João Pessoa, Paraíba, Brasil.

BRASIL. (2011). Regulamento técnico de produção, identidade e qualidade do leite. Brasília, Brasil: Ministério da Agricultura, Pecuária e Abastecimento.

Coelho, F. J. O., Quevedo, P. S., Menin, A. \& Timm, C. D. (2009). Avaliação do prazo de validade do iogurte. Ciência Animal Brasileira, 10(4):1155-1160.

Cunha Neto, O. C., Oliveira, C. A. F., Hotta, R. M. \& Sobral, P. J. A. (2005). Avaliação físico-química e sensorial do iogurte natural produzido com leite de búfala contendo diferentes níveis de gordura. Ciência e Tecnologia de Alimentos, 25(3):448-453.

Finco, A. M. O., Garmus, T. T., Bezerra, J. R. M. V. \& Córdova, K. R. V. (2011). Elaboração de iogurte com adição de farinha de gergelim Yogurt-making with addition of sesame flour. Ambiência, 7(2):217227.

Grandi, A. Z. \& Rossi, D. A. (2010). Avaliação dos itens obrigatórios na rotulagem nutricional de produtos lácteos fermentados. Revista do Instituto Adolfo Lutz, 69(1):62-68.

Leite Júnior, B. R. C. (2013). Qualidade microbiológica de alimentos de origem animal comercializados na região de Minas Gerais. Vértices, 15(2):49-59.

Lima, S. E. R. (2015). Estudo do crescimento de bactérias psicrotróficas e mesófilas em iogurte enriquecido com grãos. Caderno Verde de Agroecologia e Desenvolvimento Sustentável, 4(1):1-6.

Marshall, R. T., Goff, H. D. \& Hartel, R. W. (2003). Standard methods for the examination of dairy products (6th ed.). New York, USA: Plenum Publisher.

Matsubara, M. T., Beloti, V., Tamanini, R., Fagnani, R., Silva, L. C. C., Monteiro, A. A., . . Barros, M. A. F. (2011). Boas práticas de ordenha para redução da contaminação microbiológica do leite no agreste Pernambucano. Semina: Ciências Agrárias, 32(1).

Nörnberg, M. d. F. B. L., Tondo, E. C. \& Brandelli, A. (2009). Bactérias psicrotróficas e atividade proteolítica no leite cru refrigerado. Acta Scientiae Veterinariae, 37(2):157-163.

Oliveira, E. d. A. M., Soldi, C. L., Caveião, C. \& Sales, W. B. (2018). Contagem de bactérias láticas viáveis em leites fermentados. Revista Univap, 24(46):94-104.

Paixão, M. G., Lopes, M. A., Costa, G. M., Souza, G. N., Abreu, L. R. \& Pinto, S. M. (2017). Milk quality and financial management at different scales of production on dairy farms located in the south of Minas Gerais state, Brazil. Revista Ceres, 64(3):213-221.

Pereira, C. I., Gomes, E. O., Gomes, A. M. P. \& Malcata, F. X. (2008). Proteolysis in model Portuguese cheeses: Effects of rennet and starter culture. Food Chemistry, 108(3):862-868.

Reis, D. L., Couto, E. P. Ribeiro, J. L., Nero, L. A. \& Ferreira, M. A. (2014). Qualidade e segurança microbiológica de derivados lácteos fermentados de origem bovina produzidos no Distrito Federal, Brasil. Semina, Ciências Agrárias, 35(6), 3161-3172.

Ril, F. T., Loch, C. R., Valduga, A. T., Macedo, S. M. D. \& Cichoski, A. J. (2011). Scientific Note: biochemical profile of rats fed yogurt containing yerba mate (Ilex paraguariensis St. Hil) extract. Brazilian Journal of Food Technology, 14(4):332-337.

Rodrigues, N. P. A., Givisiez, P. E. N., Queiroga, R. C. R. E., Azevedo, P. S., Gebreyes, W. A. \& Oliveira, C. J. B. (2012). Milk adulteration: Detection of bovine milk in bulk goat milk produced by smallholders in northeastern Brazil by a duplex PCR assay. Journal of Dairy Science, 95(5):2749-2752.

Santana, E. H. W., Beloti, V., Barros, M. d. A. F., Moraes, L. B., Gusmão, V. V. \& Pereira, M. S. (2001). 
Contaminação do leite em diferentes pontos do processo de produção: I. Microrganismos aeróbios mesófilos e psicrotróficos. Semina: Ciências Agrárias, 22(2):145-154.

Santos, P. A. d., Silva, M. A. P. d., Souza, C. M. d., Isepon, J. d. S., Oliveira, A. N. d. \& Nicolau, E. S. (2009). Efeito do tempo e da temperatura de refrigeração no desenvolvimento de microrganismos psicrotróficos em leite cru refrigerado coletado na macrorregião de Goiânia, GO. Ciência Animal Brasileira, 10(4):1237-1245.

Silva, L. C. C., Beloti, V., Tamanini, R., D’Ovidio, L., Mattos, M. R., Arruda, A. M. C. T. \& Pires, E. M. F. (2011). Rastreamento de fontes da contaminação microbiológica do leite cru durante a ordenha em propriedades leiteiras do Agreste Pernambucano. Semina: Ciências Agrárias, 32(1).

Soares, D. S., Fai, A. E. C., Oliveira, A. M., Pires, E. M. F. \& Stamford, T. L. M. (2011). The use of cheese whey for probiotic yogurt production. Arquivo Brasileiro de Medicina Veterinária e Zootecnia, 63(4):996-1002.

Souza, S. M. O., Brasileiro, I. S., Carvalho, A. F., Silva Júnior, A., Nero, L. A. \& Ferreira, M. A. (2012). Using Nested PCR To Detect the hlyA Gene of Listeria monocytogenes in Minas Frescal Cow's Milk Cheese. Journal of food protection, 75(7):1324-1327.

Zeni, M. P., Maran, M. H., Silva, G. P. R., Carli, E. M. \& Palezi, S. C. (2013). Influência dos microrganismos psicrotróficos sobre a qualidade do leite refrigerado para produção de UHT. Unoesc \& Ciência-ACET, 4(1):61-70.

Recebido: 28 de março, 2019.

Aprovado: 30 de abril, 2019.

Publicado: 3 de maio, 2019.

Licenciamento: Este artigo é publicado na modalidade Acesso Aberto sob a licença Creative Commons Atribuição 4.0 (CC-BY 4.0), a qual permite uso irrestrito, distribuição, reprodução em qualquer meio, desde que o autor e a fonte sejam devidamente creditados. 